\title{
FACILIDADES E DIFICULDADES DO PROCESSO ENSINO- APRENDIZAGEM DA ENFERMAGEM PERIOPERATÓRIA NA PANDEMIA DA COVID-19 EM FORMATO ONLINE
}

https://doi.org/10.5327/Z1414-4425202100030001

0 cenário mundial instaurado pela Coronavirus Disease (COVID-19) exigiu que a sociedade transformasse hábitos, necessidades e percepções em função da pandemia. Nesse contexto, essas exigências ocorreram igualmente no processo adaptado do ensino-aprendizagem na formação de enfermeiros.

Os gestores das instituições de ensino superior (IES) e os enfermeiros docentes assumiram estratégias desafiadoras no processo de ensinar enfermagem por meio de tecnologias da informação e comunicação (TIC), ferramentas pouco utilizadas pré-pandemia, em razão de a profissão dever ser aprendida pelo aluno em processos relacionais de "gente cuidando de gente".

Diante de tantas incertezas, o ensino remoto/ online emergencial foi introduzido como uma alternativa, a fim de diminuir os danos na aprendizagem e garantir a continuidade do processo de formação dos desejados profissionais no cenário assistencial pandêmico.

Estudo apontou que a imposição do ensino online estabelece limitações para os alunos mais velhos, que vivem em áreas rurais, com responsabilidades profissionais e familiares e com recursos eletrônicos limitados, pois a educação online vai além da continuação das aulas presenciais ${ }^{1}$.

Outra pesquisa demonstrou que os estudantes tiveram, assim como os docentes, de se adaptar a uma rotina nos domicílios, mesmo havendo manutenção dos dias e turnos já programados anteriormente ao período da pandemia. Isso porque a família, de modo geral, também vem desenvolvendo atividades remotas, seja no trabalho (home office), seja nas escolas de ensino infantil, fundamental, médio e superior. Somam-se, ainda, os afazeres domésticos e a necessidade de lidar com a presença dos filhos em tempo integral no espaço do lar, que também funcionam como distratores para o aprendizado ${ }^{2}$.

Os desafios de longa data ficaram emergentes com a pandemia. Para muitos docentes e discentes, o uso de novas tecnologias foi mais uma barreira a ser vencida, além das demais adversidades trazidas pela pandemia.
Ainda que essas dificuldades tenham sido enfrentadas com coragem e compromisso, é oportuno refletir como eram nossas aulas nas universidades antes da pandemia. Os cenários práticos eram de fato aproveitados? Os docentes ofertavam atualidades na área que ensinam? O ensino presencial de fato aproximava? Como o uso da tecnologia na educação pode ser um aliado? Ainda que as tecnologias no ensino tenham sido absorvidas, é necessário refletir sobre a abordagem pedagógica que o professor propicia, e não apenas a tecnologia em si. Deve-se entender que a tecnologia não é uma ferramenta autossuficiente; sua aplicação pura e simples não solucionará todos os problemas inerentes ao ensino ${ }^{3}$.

Atualmente, seguimos no processo de avaliação do ensino oferecido em 2020, resgatando possíveis prejuízos de conteúdo aos alunos, reestruturação, reposição das atividades práticas e formação contínua dos professores para o aprimoramento do uso das TIC.

Até esse momento, um cenário de grandes transformações persiste, com a permanência das tecnologias contemporâneas na formação da enfermagem perioperatória em diversas faces: graduação, pós-graduação, educação permanente nas instituições de saúde, associações e conselhos de classe.

Cada vez mais, o mundo do trabalho exerce uma pressão nos serviços de enfermagem, pela busca de profissionais competentes para assumir as diversas áreas de atuação no perioperatório. Dessa forma, a responsabilidade da formação e preparação desses profissionais não pode ser desconsiderada, mesmo num momento desafiador como esse. O que se vislumbra para a educação em enfermagem é a emergência de tecnologias de interface que articulem o físico e o digital e que ampliem o debate, a troca de experiências, a interação, a reflexão e o pensamento crítico ${ }^{4}$.

As adaptações educacionais ante a pandemia foram pertinentes para a continuidade da formação acadêmica, contudo em cursos como a enfermagem não se devem renunciar recursos que assegurem a interação entre as pessoas. Isso porque há um caráter prático imbuído na profissão que, por lidar 
com o processo saúde-doença, requer desenvolvimento e/ou aprimoramento de habilidades específicas para o cuidado ${ }^{4,5}$.

Em tempos de pós-pandemia, tem de se rememorar que o cuidado de enfermagem é presencial e indispensável. Assim, a formação de profissionais para cuidar de vidas humanas deve ser construída e fundamentada nesse preceito.

Cada um de nós tem um papel a desempenhar na defesa da saúde de nossas comunidades e no apoio aos enfermeiros em todos os lugares. Em meio a todas as incertezas sobre o vírus e quanto tempo pode demorar até que a vida comece a voltar ao novo normal, a formação de profissionais de enfermagem ganhará novas tecnologias de educação, e tais profissionais sairão do outro lado dessa pandemia mais fortes e mais bem preparados para enfrentar novos desafios.
Simone Garcia Lopes $\bullet$

Doutoranda do Programa de Pós-Graduação em Enfermagem na Saúde do Adulto (PROESA) pela Escola de Enfermagem da Universidade de São Paulo (EE-USP). Professora do curso de Graduação em Enfermagem do Centro Universitário Faculdade de Medicina ABC (FMABC) e diretora de Assistência da SOBECC Nacional (gestão 2019-2021).

Soraya Palazzo

Mestre em Saúde do Adulto pela EE-USP. Coordenadora dos cursos de Pós-Graduação de Enfermagem em Centro de Material

Esterilizado, Centro Cirúrgico e Recuperação Anestésica e de Pós-Graduação Multiprofissional em Oncologia do Centro Universitário São Camilo e diretora de Eventos Regionais da SOBECC Nacional (gestão 2019-2021).

\section{REFERÊNCIAS}

1. Ramos-Morcillo AJ, Leal-Costa C, Moral-García JE, RuzafaMartínez M. Experiences of nursing students during the abrupt change from face-to-face to e-learning education during the first month of confinement due to COVID-19 in Spain. Int J Environ Res Public Health. 2020;17(15):5519. https://doi.org/10.3390/ ijerph 17155519

2. Bastos MC, Canavarro DA, Campos LM, Schulz RS, Santos JB, Santos CF. Ensino remoto emergencial na graduação em enfermagem: relato de experiência na COVID-19. REME [Internet]. 2020 [acessado em 9 set. 2021].;24:e1335. [Disponível em: https://pesquisa.bvsalud.org/ portal/resource/pt/biblio-1135978

https://doi.org/10.5935/1415.2762.20200072
3. Bezerra IMP. State of the art of nursing education and the challenges to use remote technologies in the time of coronavirus pandemic. J Hum Growth Dev. 2020;30(1):141-7. https://doi.org/10.7322/jhgd.v30.10087

4. Lira ALBC, Adamy EK, Teixeira E, Silva FVD. Nursing education: challenges and perspectives in times of the COVID-19 pandemic. Rev Bras Enferm. 2020;73(Supl. 2):e20200683. https://doi. org/10.1590/0034-7167-2020-0683

5. Prado C, Santiago LC, Silva JA, Pereira IM, Leonello VM, Otrenti E, et al. Ambiente virtual de aprendizagem no ensino de enfermagem: relato de experiência. Rev Bras Enferm. 2012;65(5):862-6. https:// doi.org/10.1590/S0034-71672012000500022 